\author{
Universität Zürich \\ Zentrum für Zahnmedizin \\ Dental Materials Unit, Clinic for Fixed and Removable Prosthodontics \\ and Dental Materials Science
}

Direktor: Prof. Dr. med. dent. Christoph Hämmerle

Arbeit unter Leitung von Prof. Dr. med. dent. Mutlu Özcan, Ph.D

\title{
Adhesion of resin composite to enamel and dentin: A methodological assessment
}

INAUGURAL-DISSERTATION

zur Erlangung der Doktorwürde der Zahnmedizin

der Medizinischen Fakultät

der Universität Zürich

vorgelegt von

Lukas Bracher

Genehmigt auf Antrag von Prof. Dr. med. dent. Christoph Hämmerle Zürich 2017 


\section{Publikationshinweis}

Adhesion of resin composite to enamel and dentin: a methodological assessment

Publiziert am: 25. Juli 2017

Journal: Im Journal of Adhesion Science and Technology,

DOI: 10.1080/01694243.2017.1354494

http://dx.doi.org/10.1080/01694243.2017.1354494 


\title{
Adhesion of resin composite to enamel and dentin: a methodological assessment
}

\author{
Lukas Bracher and Mutlu Özcan \\ Dental Materials Unit, Center for Dental and Oral Medicine, Clinic for Fixed and Removable Prosthodontics and \\ Dental Materials Science, University of Zürich, Zürich, Switzerland
}

\begin{abstract}
This study compared the impact of four test methods on adhesion of resin composite to enamel and dentin. Human molars $(N=54)$ were randomly assigned to test the adhesion of resin composite material (Quadrant Universal LC) using one of the following test methods: (a) macroshear test (SBT; $n=16)$, (b) macrotensile test (TBT; $n=16$ ), (c) microshear test ( $\mu \mathrm{SBT} ; n=16)$ and (d) microtensile test $(\mu \mathrm{TBT} ; n=6)$. In a randomized manner, buccal or lingual surfaces of each tooth, were assigned as enamel or dentin substrates. Enamel and dentin surfaces were conditioned using an etch-and-rinse adhesive system (Syntac Classic). After storage $\left(24 \mathrm{~h}, 37^{\circ} \mathrm{C}\right)$, bond tests were conducted in a Universal Testing Machine ( $1 \mathrm{~mm} / \mathrm{min}$ ) and failure types were analyzed. Data were analyzed using Univariate and Tukey`s, Bonneferroni tests $(a=0.05)$. Two-parameter Weibull modulus, scale $(\mathrm{m})$ and shape (0) were calculated. Test method $(p<0.001)$ and substrate type $(p<0.001)$ significantly affected the results. When testing adhesion of resin composite to enamel, SBT $(25.9 \pm 5.7)^{\mathrm{a}}$, TBT $(17.3 \pm 5.1)^{\mathrm{a}, \mathrm{c}}$ and $\mu \mathrm{SBT}$ $(27.2 \pm 6.6)^{\mathrm{a}, \mathrm{d}}$ test methods showed significantly higher mean bond values compared to $\mu$ TBT $(10.1 \pm 4.4)^{\mathrm{b}}(p<0.05)$. Adhesion of resin composite to dentin did not show significant difference depending on the test method ( $12 \pm 5.7-20.4 \pm 4.8 ; p>0.05)$. Only with SBT, significant difference was observed for bond values between enamel ( $25.9 \pm 5.7)$ and dentin $(12 \pm 5.7 ; p<0.05)$. Weibull distribution presented the

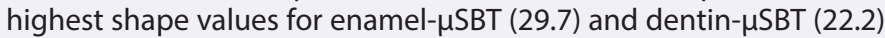
among substrate-test combinations. Regardless of the test method, cohesive failures in substrate were more frequent in enamel (19.1\%) than in dentin (9.8\%).
\end{abstract}

\section{ARTICLE HISTORY}

Received 4 August 2016

Revised 5 July 2017

Accepted 7 July 2017

\section{KEYWORDS}

Adhesion; dentin; enamel; macroshear; macrotensile; microshear; microtensile; resin composite; test method

\section{Introduction}

Advances in adhesive technologies during the last few decades introduced large number of resin-based materials for direct and indirect dental application that could be adhered to enamel or dentin. Reliable adhesion of the resin composites to enamel becomes particularly important in bonding brackets to non-prepared enamel surfaces in orthodontics or bonding surface-retained restorations or fixed dental prosthesis (FDP) where no macromechanical 
retention is available. Likewise, durable adhesion to dentin is required for minimal invasive applications after tooth preparation as a consequence of caries removal, for restoring tissue loss due to trauma and bonding partial to full coverage crowns or FDPs.

Adhesion to enamel is typically achieved after etching enamel with $\mathrm{H}_{3} \mathrm{PO}_{4}$ that creates a highly micro-retentive surface that is easily wetted by hydrophobic resin-based adhesives [1]. The adhesive resin then penetrates the etched surface through capillary action and subsequent polymerization of the resin facilitates micromechanical adhesion. Most commercially available enamel etching agents have a concentration ranging between 30 and $40 \%$. When the concentration is less, the dicalcium phosphate dihydrate precipitate forms in the enamel surface that is very difficult to remove by rinsing [1]. For orthodontic applications, enamel tissue removal is not needed but for some applications in reconstructive dentistry, minimal room has to be created for the material that eventually necessitates the removal of surface enamel using mechanical methods such as the use of diamond burs, disks or airborne particle abrasion. The next step after micromechanical roughening of the enamel is the application of the adhesive resin where the conditioned surface provides the foundation for better wettability of the adhesive resin and the following resin composite $[2,3]$.

Adhesion to dentin on the other hand, is best achieved using 'etch-and-rinse' adhesive systems that rely on the application of adhesive monomers to acid-etched dentin [4-6]. The use of simplified self-etching, self-priming agents that contain hydrophilic and acidic monomers, acidic molecules, diluent monomers, photoinitiators, and solvents with usually low $\mathrm{pH}$ could also simultaneously etch the dentin and allow infiltration of the adhesive monomers into the dentin [7]. However, previous studies have shown that self-etch adhesives may result in lower bond strength to dentin and result in more permeability compared to etch-and-rinse adhesive systems [7]. Demineralization of the dentin substrate and penetration of the resin monomers create micromechanical retention that further contributes to the overall adhesion [4-6].

Meta-analysis in the field of adhesion in dentistry signified that depending on the test method employed and the variation in chemical compositions, bond strength of resin based materials to dentin between 9 and $45.3 \mathrm{MPa}$ [8]. Today, an increased number of adhesive materials are being offered for clinical use. Neither ethically, nor technically it is possible to test their performance in randomized controlled clinical trials. Therefore, preclinical evaluations help to rank their adhesive properties. For this purpose several testing methodologies, (i.e. macroshear, microshear, macrotensile, and microtensile tests) have been suggested for evaluation of the bond strength of resin-based materials to dental tissues. Technically in macro bond tests, the bonded area is more than $3 \mathrm{~mm}^{2}$ and in micro test set-ups it is less then $3 \mathrm{~mm}^{2}$ [9]. According to the Griffith's theory [10], the tensile strength of the uniform materials decreases when the specimen size is increased. In that respect, the type of test method also affects the achieved bond strength and thereby, ranking of resin based materials. Unfortunately, to date, limited number of studies compared several test methods in one study or used enamel as a control substrate when testing dentin adhesives $[8,11]$.

Since the adhesive joints in clinical applications are subjected to both shear and tensile form of forces during chewing, the objectives of this study were to evaluate the adhesion of resin composite to enamel and dentin using macro- and micro-shear and tensile adhesion methods and to evaluate the failure types after debonding. The null hypotheses tested were that bond strength results would not show significant difference depending on the test method and the substrate type. 
Table 1. The brands, manufacturers and chemical compositions of the main materials used in this study.

\begin{tabular}{|c|c|c|}
\hline Brand & Manufacturer & Chemical composition \\
\hline Total etch & Ivoclar vivadent & $37 \%$ phosphoric acid, water \\
\hline Syntac primer & Ivoclar vivadent & $\begin{array}{l}\text { Acetone } 25-50 \% \text {, Triethylenglycoldimethacrylate } \\
10-<25 \% \text {, Polyethylenglycoldimethacrylate } 3-<10 \% \text {, } \\
\text { Maleic acid }(3-<10 \%)\end{array}$ \\
\hline Syntac adhesive & Ivoclar vivadent & $\begin{array}{l}\text { Polyethylenglycoldimethacrylate } 25-50 \% \text {, Glutaralde- } \\
\text { hyde } 3-<10 \%\end{array}$ \\
\hline Heliobond & Ivoclar vivadent & $\begin{array}{l}\text { bis-GMA (50-100), Triethylenglycoldimethacrylate } \\
(25-50 \%)\end{array}$ \\
\hline Qadrant universal LC & Cavex, Haarlem, The Netherlands & $\begin{array}{l}\text { Feldspar } 20-<25 \% \text {, bis-phenol A Diglycidyl Methacrylate } \\
\text { (bis-GMA) } 10-20 \% \text {, Silica, fused }(0.1-<=2.5 \%)\end{array}$ \\
\hline
\end{tabular}

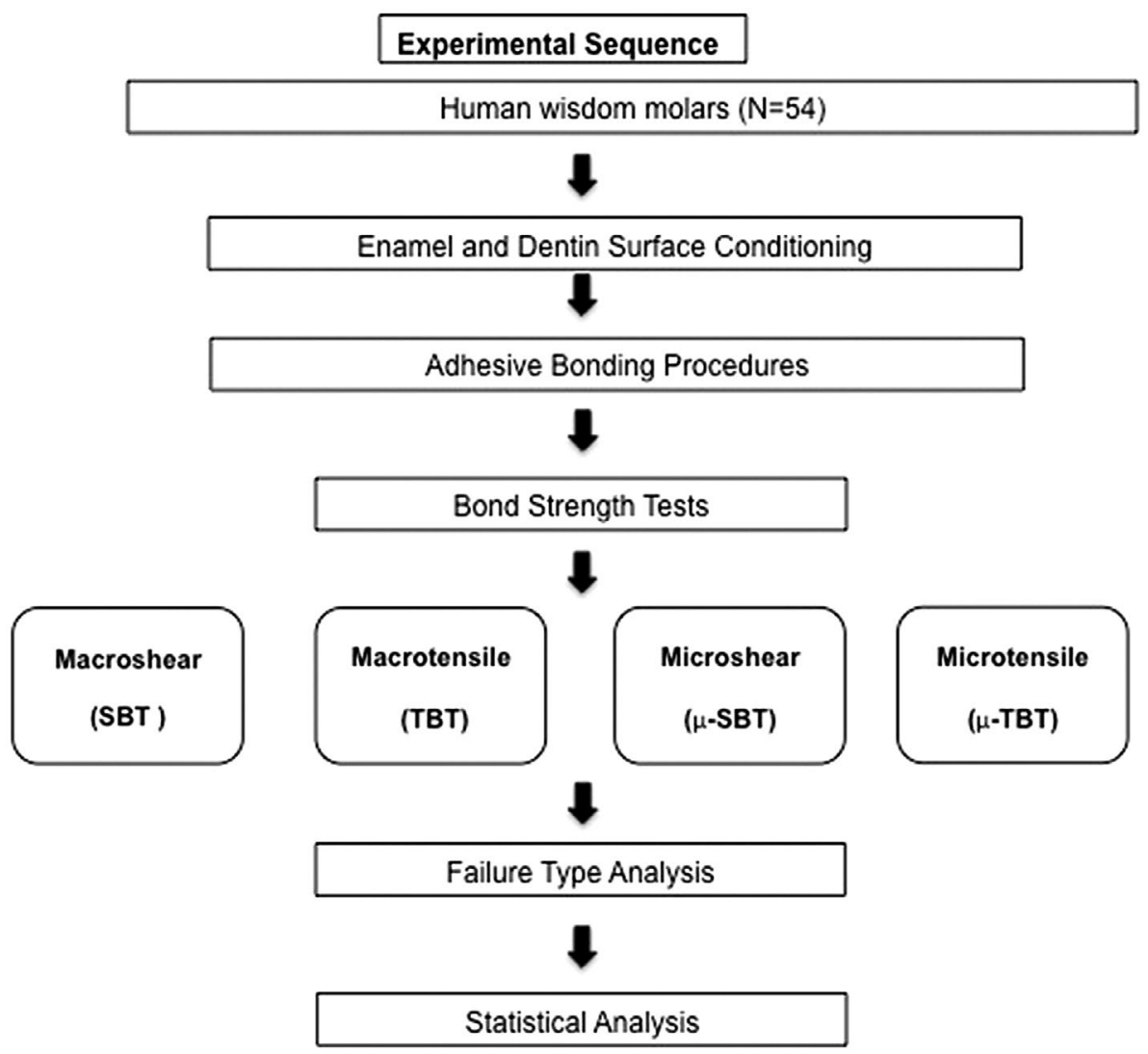

Figure 1. Flow-chart showing experimental sequence and allocation of groups.

\section{Materials and methods}

The brands, types, manufacturers and chemical compositions of the materials used in this study are listed in Table 1. Distribution of experimental groups based on the substrate type and test methods and sequence of experimental procedures are presented in Figure 1. 


\section{Specimen preparation}

Human wisdom molars $(N=54)$, were collected and kept in distilled water at $5{ }^{\circ} \mathrm{C}$ until the experiments. All teeth used in the present study were extracted for reasons unrelated to this project. Written informed consent for research purpose of the extracted teeth was obtained by all donors prior to extraction according to the directives set by the National Federal Council. Ethical guidelines were strictly followed and irreversible anonymization was performed in accordance with State and Federal Law [12-14]. After tissue remnants were removed with a scaler $(\mathrm{H} 6 / \mathrm{H} 7$; Hu-Friedy, Chicago, IL), teeth were stored in $0.5 \%$ Chloramin $\mathrm{T}$ for 2 weeks. The roots of the teeth were embedded in a polyvinyl chloride (PVC) mould using auto-polymerizing acrylic resin (Scandiquick, Scandia, Hagen, Germany) allowing their buccal and lingual surfaces exposed for bonding purposes. Number of specimens for each tests were as follows: macroshear test (SBT; $n=16)$, macrotensile test (TBT; $n=16)$, microshear test ( $\mu$ SBT; $n=16$ ) and microtensile test ( $\mu$ TBT; $n=6, n_{\text {sticks- }}$ enamel $\left.: 52, n_{\text {sticks-dentin }}: 43\right)$. In a randomized manner, buccal or lingual surfaces of each tooth, were assigned as enamel or dentin substrates. Enamel and dentin surfaces were prepared and conditioned according to the technical specification ISO/TS 11405 as follows [15]:

\section{Enamel preparation}

The enamel surfaces of each tooth were conditioned with etch and rinse adhesive system (Syntac Classic, Ivoclar Vivadent, Schaan, Liechtenstein) according to the manufacturer's recommendations. Firstly, the enamel was etched for $60 \mathrm{~s}$ with $37 \% \mathrm{H}_{3} \mathrm{PO}_{4}$, rinsed for $\mathrm{s}$ and then gently air-dried for $5 \mathrm{~s}$. Then, adhesive resin (Heliobond, Ivoclar Vivadent) was applied with a brush for $20 \mathrm{~s}$, air-thinned for $3 \mathrm{~s}$ and photo-polymerized for $40 \mathrm{~s}$ using an LED polymerization unit (Bluephase, Ivoclar Vivadent) from a constant distance of $2 \mathrm{~mm}$ from the surface.

\section{Dentin preparation}

Buccal and lingual surfaces were trimmed (Isomet, Buehler Ltd., Lake Bluff, IL, USA) under water-cooling until flat dentin surfaces were achieved. Dentin level after flattening was considered as superficial dentin. One mm below this level was indicated and considered as deep dentin [16]. Dentin surfaces were then ground finished using 600-grit silicon carbide papers (Stuers A/S, Ballerup, Denmark) under water-cooling and then rinsed thoroughly in order to create bonding surfaces covered with smear layer [17]. Three-step etch-and-rinse adhesive system (Syntac, Ivoclar Vivadent) was used for dentin conditioning. First, primer (Syntac Primer, Ivoclar Vivadent) was applied using microbrushes for $30 \mathrm{~s}$, air thinned gently with oil-free air. Then adhesive (Syntac Adhesive, Ivoclar Vivadent) was applied for $30 \mathrm{~s}$, air thinned and finally bonding agent (Heliobond, Ivoclar Vivadent) was applied, air-thinned according to the manufacturer's instructions and photo-polymerized (Bluephase, Ivoclar Vivadent) for $40 \mathrm{~s}$. Light intensity was assured to be higher than $1200 \mathrm{~mW} / \mathrm{cm}^{2}$, verified by a radiometer after every 8 specimen (Model 100, Kerr, Orange, CA, USA). 


\section{Bonding procedures for $S B T, T B T, \mu S B T$}

One calibrated operator carried out adhesive procedures throughout the experiments. Translucent polytetrafluoroethylene (Teflon) molds (DuPont, Saint-Gobain, France; for SBT: height: $4 \mathrm{~mm}$, diameter: $2.9 \mathrm{~mm}$; for TBT: height: $4 \mathrm{~mm}$, diameter: $3 \mathrm{~mm}$; for $\mu S B T$ : height: $4 \mathrm{~mm}$, diameter: $0.8 \mathrm{~mm}$ ) were stabilized on the enamel or dentin specimens in a custom made device. The mold was filled with the resin composite (Quadrant Universal AC, Cavex, Haarlem, The Netherlands, Shade A3), a metal pin was inserted to ensure $100 \mu \mathrm{m}$ thickness at the first layer of the increment and it was photo-polymerized (Bluephase, Ivoclar Vivadent). The mold was filled in two increments and polymerized for $40 \mathrm{~s}$ from 5 directions from a distance of $2 \mathrm{~mm}$. Oxygen inhibiting gel (Oxyguard, Kuraray, Tokyo, Japan) was applied at the bonded margins and rinsed with copious water after $1 \mathrm{~min}$.

\section{Bonding procedures for $\mu T B T$}

Each tooth with exposed dentin surfaces was duplicated with resin composite (Quadrant Universal AC, Cavex) using a mold made out of condensation curing polysiloxane, putty soft consistency impression material (Alphasil Perfect, Müller-Omicon, Cologne, Germany). Resin composite was incrementally condensed into the mold and each layer was photo-polymerized (Bluephase, Ivoclar Vivadent) for $40 \mathrm{~s}$. As a result, the bonding surface area of the resin composite blocks had the same surface area with the dentin surfaces. One composite resin block was fabricated for each tooth. Initially, the resin composite-dentin assembly was fixed with cyanoacrylate adhesive (Super Bonder Gel, Loctite Ltd., São Paulo, Brazil) on cylindrical metallic base of the cutting machine. The calibration of the machine was repeated for each new specimen. Bar specimens (sticks) were obtained by cutting the assembly using steel diamond discs (Accutom-50, Stuers A/S, Ballerup, Denmark) at low speed under water-cooling. The external sections of $1 \mathrm{~mm}$ were eliminated due to possible excess or absence of resin composite. The blocks were turned $90^{\circ}$ and fixed again on the metallic base. Four transversal sections were obtained from each dentin-composite block and from those sections sticks with a length of $\pm 8 \mathrm{~mm}$ and adhesive area of $\pm 1 \mathrm{~mm}^{2}$ were obtained. Thus, only the central specimens were used for the experiments. These sticks were examined under an optical microscope (Zeiss MC 80 DX, Jena, Germany) at $\times 50$ magnification and only those crack-free, structurally intact ones were selected for the experiments. In total, 52 sticks were obtained from enamel and 43 from dentin group. Bonding area of each stick specimen was measured before the tests using a digital caliper with an accuracy of $100 \mu \mathrm{m}$.

\section{Storage conditions}

The specimens were stored in an incubator (Binder GmbH, Tuttlingen, Germany) at $37^{\circ} \mathrm{C}$ for $24 \mathrm{~h}$ and then subjected to bond tests.

\section{Macroshear and macrotensile tests}

For the SBT, $\mu$ SBT, specimens were mounted in the jig of the Universal Testing Machine (Zwick ROELL Z2.5 MA 18-1-3/7, Ulm, Germany) and the shear force was applied using a shearing blade for SBT and a metal wire for $\mu \mathrm{SBT}$ to the adhesive interface until failure 
occurred. The load was applied to the adhesive interface, as close as possible to the surface of the substrate at a crosshead speed of $1 \mathrm{~mm} / \mathrm{min}$ and the stress-strain curve was analyzed with the software program (TestXpert, Zwick ROELL, Ulm, Germany). For the TBT, specimens were mounted in the corresponding jig and resin composite disc was pulled with a grip from the substrate surface at a crosshead speed of $1 \mathrm{~mm} / \mathrm{min}$. For the $\mu$ TBT, the sticks were fixed to the alignment device with one drop of cyanoacrylate glue (Super Bonder Gel) on the resin composite and one on the dentin part of the bar specimen. It was made sure that the adhesive interface was free of the glue. The tensile force was applied at a cross-head speed of $1 \mathrm{~mm} / \mathrm{min}$ until debonding.

\section{Microscopic evaluation and failure type analysis}

After adhesion tests, debonded specimen surfaces were analysed for failure types using an optical microscope (Zeiss MC 80 DX, Jena, Germany) at ×50 magnification. Failure types were classified as follows: Score 1: Cohesive1: Cohesive failure in the substrate, Score 2: Mixed 1: Combination of adhesive and cohesive failure types in the substrate and bonding agent, Score 3: Adhesive: Adhesive failure of bonding agent from the resin composite surface with no remnants on the resin composite, Score 4: Mixed2: Combination of adhesive and cohesive failure types in the bonding agent and resin composite, Score 5: Cohesive2: Cohesive failure in the resin composite.

\section{Statistical analysis}

According to the two-group Satterthwaite t-test (SPSS Software V.20, Chicago, IL, USA) with a 0.05 two-sided significance level, a sample size of 15 in each experimental group was calculated to provide more than $80 \%$ power to detect a difference of $7.45 \mathrm{MPa}$ between mean values. Kolmogorov-Smirnov and Shapiro-Wilk tests were used to test normal distribution of the data. As the data were normally distributed, Univariate analysis of variance was applied to analyze possible differences between the groups where the bond strength was the dependent variable and substrate type (2 levels: enamel vs. dentin) and test methods (4 levels: SBT, TBT, $\mu$ SBT, $\mu$ TBT as independent variables). Interactions of substrate materials and test methods were analyzed using Tukey's or Dunnett-T3 post hoc tests. Following Anderson-Darling tests, maximum likelihood estimation without a correction factor was used for two-parameter Weibull distribution to interpret predictability and reliability of adhesion (Minitab Software V.16, State College, PA, USA) and a two-sided $\chi^{2}$ was used to compare the results. Statistical analyses of failure types were made using $\chi^{2}$ test. $P$ values less than 0.05 were considered to be statistically significant in all tests.

\section{Results}

Pre-test failures during cutting procedures in $\mu$ TBT were considered as $0 \mathrm{MPa}$.

While test method $(p<0.001)$, substrate type $(p<0.001)$ significantly affected the bond results, interaction terms were not significant $(p=0.237)$.

When testing adhesion of resin composite to enamel, SBT $(25.9 \pm 5.7)^{\mathrm{a}}$, TBT $(17.3 \pm 5.1)^{\mathrm{a}, \mathrm{c}}$ and $\mu$ SBT $(27.2 \pm 6.6)^{\text {a,d }}$ test methods showed significantly higher mean bond values 
compared to $\mu$ TBT $(10.1 \pm 4.4)^{\mathrm{b}}(p<0.05$; Table 2$)$. Adhesion of resin composite to dentin did not show significant difference depending on the test method (12 $\pm 5.7-20.4 \pm 4.8$; $p>0.05)$.

Only with SBT, significant difference was observed for bond values between enamel $(25.9 \pm 5.7)$ and dentin $(12 \pm 5.7 ; p<0.05)$ while within each type of test method, mean bond strength to enamel and dentin did not show significant difference $(p>0.05$; Table $3 a-3 c)$.

Weibull distribution presented the highest shape values for enamel-SBT $(5.25) / \mu$ SBT (4.65) and dentin- $\mu$ SBT (4.86) among substrate-test combinations.

With $\mu$ TBT, pre-test failures were more commonly experienced with enamel than with dentin. Failure types showed significant differences between enamel and dentin $(p<0.05)$. Regardless of the test method, cohesive failures in substrate were more frequent in enamel (19.1\%) than in dentin (9.8\%).

\section{Discussion}

This study was undertaken in order to evaluate the adhesion of resin composite to enamel and dentin using macro- and micro-shear and tensile adhesion methods and to evaluate the failure types after debonding. Since both the substrate type and the test method significantly affected the bond strength results, the null hypotheses tested could be rejected.

In order to measure the bond strength values between an adherent and a substrate accurately, it is crucial that the bonding interface should be the most stressed region, regardless of the test methodology being employed. Previous studies using stress distribution analyses have reported that some of the bond strength tests do not appropriately stress the interfacial zone $[18,19]$. Shear tests have been criticized for the development of non-homogeneous stress distributions at the bonded interface, inducing either underestimation or misinterpretation of the results, as the failure often starts in one of the substrates and not solely at the adhesive zone $[18,19]$. Conventional tensile tests also present some limitations, such as the difficulty of specimen alignment and the tendency for heterogeneous stress distribution at the adhesive interface. On the other hand, when specimens are aligned correctly, the microtensile test shows more homogeneous distribution of stress, and thereby more sensitive comparison or evaluation of bond performances [20]. However, minute deviations in specimen alignment in the jig may cause increase bond strength due to shear component being introduced during deboning bonded joints [20]. According to the Griffith's theory [10], the tensile strength of the uniform materials decreases when the specimen size is increased. This outcome is a function of the distribution of defects in the material, since the larger bonded areas of the beams have more defects than smaller specimens. Overall, adhesion related studies in dentistry, bonded surface areas range from $3 \mathrm{~mm}^{2}$ to $1 \mathrm{~mm}^{2}$ in macro- and micro-test methods, respectively [9]. Due to the reduced bonded area and more homogeneous distribution of stresses, micro-test methods tend to show significantly higher bond strength results than the macro-test methods. This could eventually affect the ranking of materials being tested in one study [11]. To the best of our knowledge, no study exists to date where all four types of adhesion tests are employed in one study on both enamel and dentin.

Based on the results of this study, significantly higher results were obtained for bond strength of resin composite to enamel with SBT, TBT and $\mu$ SBT methods than with $\mu$ TBT. Interestingly, the smaller size of the bonded area did not necessarily resulted in higher 


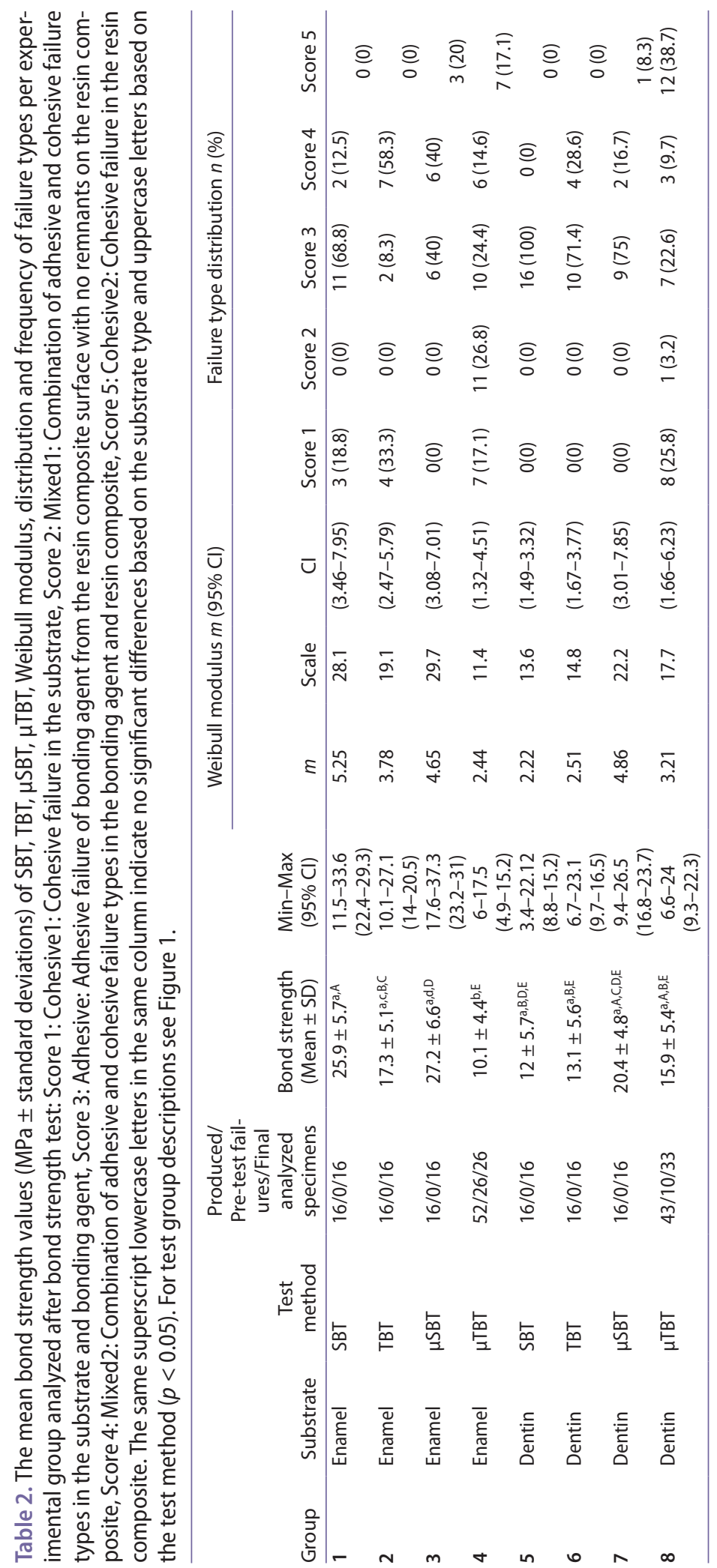


Table 3a. Significant differences between mean bond strengths of resin composite to enamel based on the test method (Tukey's and 2-sided Dunnett-T post hoc tests, $a=0.05$ ). For group descriptions see Figure 1.

\begin{tabular}{lcccc}
\hline Enamel & SBT & TBT & $\mu$ SBT & $\mu$ TBT \\
\hline SBT & - & 0.067 & 1.000 & 0.000 \\
TBT & 0.67 & - & 0.020 & 0.566 \\
$\mu$ SBT & 1.000 & 0.020 & - & 0.000 \\
$\mu$ TBT & 0.000 & 0.566 & 0.000 & - \\
\hline
\end{tabular}

Table 3b. Significant differences between mean bond strengths of resin composite to dentin based on the test method (Tukey's and 2-sided Dunnett-T post hoc tests, $a=0.05$ ).

\begin{tabular}{lcccc}
\hline Dentin & SBT & TBT & $\mu$ SBT & $\mu$ TBT \\
\hline SBT & - & 1.000 & 0.085 & 0.970 \\
TBT & 1.000 & - & 0.245 & 0.996 \\
$\mu$ SBT & 0.085 & 0.245 & - & 0.946 \\
$\mu$ TBT & 0.970 & 0.996 & 0.946 & - \\
\hline
\end{tabular}

Table 3c. Cross-comparison of significant differences between mean bond strengths of resin composite for enamel vs. dentin based on the test method (Tukey's and 2-sided Dunnett-T post hoc tests, $a=0.05$ ).

\begin{tabular}{lcccc}
\hline Enamel vs. Dentin & SBT & TBT & $\mu S B T$ & $\mu$ TBT \\
\hline SBT & 0.000 & 0.000 & 0.564 & 0.114 \\
TBT & 0.624 & 0.865 & 0.981 & 1.000 \\
HSBT & 0.000 & 0.000 & 0.297 & 0.046 \\
$\mu$ TBT & 1.000 & 0.993 & 0.129 & 0.901 \\
\hline
\end{tabular}

bond strength, namely both SBS (25.9 MPa) and $\mu$ SBT (27.2 MPa) conveyed similar results, also supported by Weilbull moduli with 5.25 and 4.65, respectively. Although $\mu$ TBT offers bonded areas of 1 to $1.2 \mathrm{~mm}^{2}$, the complex nature of specimen preparations yields to pre-test failures [21]. In this study, the lost specimens during cutting procedures, were considered as $0 \mathrm{MPa}$ to represent the worse-case scenario during statistical analysis. In some studies, such debonded specimens were completely excluded from statistical analysis yielding to higher bond strength results. In fact, pre-test failures could be indicative for less favourable bond strength. However, this statement has to be connected to the substrate type in that bond strength results were favourable with all three test methods (SBT, TBT and $\mu$ SBT) but not $\mu$ TBT with the same adhesive and resin composite combination. Moreover, the incidence of pre-test failures with enamel was more common than with dentin. This could be also attributed to the high hardness of enamel (270-350 KHN) compared to dentin (50-70 KHN) [22] which caused deflexion of the substrate from the composite block during cutting procedures, which was not related to the bond strength. It also has to be noted that in this study, neither the composite block nor the whole tooth was secured in acrylic [21]. Thus, this approach could be considered as a worse case scenario, when testing adhesion of resin materials to dentin.

In general in adhesive dentistry, adhesion values to enamel are considered as gold standard as the etched enamel surface provides excellent micromechanical retention. Yet, it has to be realized that enamel is a crystalline substance that consists of hydroxyapatite arranged in prisms that comprises $96 \mathrm{wt} \%$ inorganic matter, $0.4-0.8 \mathrm{wt} \%$ organic matter such as proteins, lipids, carbohydrates or lactate and 3.2-3.6 wt\% water [1] and the histological 
structure of these hydroxyapatite crystals of enamel in cross section is hexagonal. From lateral perspective, they appear as small rods, of which each is built out of about 100 crystals [2]. However, they may also appear as prisms and in the centre of the prisms, the crystals are placed parallel to the longitudinal axis and in the outer parts in almost $90^{\circ}$ inclination [2]. This change in direction gives the prisms a honeycomb shape structure and the interprismatic areas consist of more loosely packed and randomly oriented crystals surrounded by a higher quantity of water and inorganic matter. Thus, enamel microstructure is in fact not a homogeneous structure and anatomical variations could be observed on enamel surface also sometimes due to the presence of aprismatic enamel layer [2].

Using conventional etch-and-rinse adhesive approach selectively dissolves hydroxyapatite crystals through etching with $37 \% \mathrm{H}_{3} \mathrm{PO}_{4}$ followed by polymerization of resin that is readily absorbed by capillary reaction within the created etch prisms [23]. Adhesive system used in this study was never tested in conjunction with TBT and $\mu$ SBT on enamel. However, our results with SBT, comply well with the findings of other studies $(21.6 \pm 5.8-29.2 \pm 7.3 \mathrm{MPa})$ in combination with other resin composites [24-28] except with one study where higher mean value was reported $(42.9 \pm 9 \mathrm{MPa})[23]$. $\mu$ TBT results for enamel could be compared with only one study where higher mean bond strength was reported (38.9 $\pm 9.2 \mathrm{MPa})$ [29]. In that study, pre-test failures were not involved in statistical analysis and similar to this study, more frequent microcracks were observed in enamel than in dentin that was also attributed to flaw introduction during preparation [30].

Similar to adhesion to enamel, bonding to dentin was achieved using an etch-and-rinse adhesive approach where hydroxyapatite crystals are selectively dissolved that is followed by resin polymerization. Unlike enamel, dentin consists only of about $68 \%$ inorganic hydroxyapatite where the rest is mostly organic collagen fibers. The primary bonding mechanism to dentin is primarily diffusion based and depends highly on hybridization or infiltration of resin within the exposed collagen fiber scaffold. Thus, true chemical bonding to dentin is fairly unlikely since the functional groups of monomers have only weak affinity to the hydroxyapatite-depleted collagen [23]. As a result of the higher organic fraction and other specifications dentin bonding is much more complex and therefore more technique sensitive than enamel bonding. Over etching or over drying dentin could also lead to collapse of collagen fibers and thereby weaken bond strength [29]. In this study, selective etching approach was employed for dentin using mild maleic acid (Syntac Primer) and subsequently dentin was rehydrated with adhesive resin (Syntac Adhesive) that is water-based. In the dentin group, the test method did not significantly affect the results. However, $\mu S B T$ showed more reliable Weilbul modulus with 4.86 compared to those of other test methods (2.22-3.21). No $\mu$ SBT results could be found in the literature with the adhesive system tested. However, with SBT $(10.2-19.45 \pm 5.04)[28,31-34]$ and with TBT wide ranges of mean values were reported $(3.89 \pm 3.47-23.8)$ [28,31-34]. One possible explanation for this wide range could be attributed to the resin composite used as the elasticity modulus of the materials show variations in different studies. Nevertheless, with the exception of $\mu$ SBT (4.86), overall Weilbull moduli for adhesion to dentin (2.22-3.21) was lower than for enamel. Similar moduli were reported for SBT and TBT using the same adhesive system $[35,36]$.

In this study, adhesion procedures were performed complying with ISO/TS 11405 specifications [15] that are frequently disregarded in adhesion studies. In this regard, one important aspect in bonding to dentin is the density and orientation of dentin tubuli. Accordingly, buccal dentin was used as a substrate according to the specifications. However, when occlusal 
dentin is used as a substrate and perfusion simulations are performed, significantly lower results could be obtained to dentin especially in deep dentin closer to the pulp with SBT $(8 \pm 3.7)$ or TBT $(2.6 \pm 1.4-5.08 \pm 3.69)$ tests $[24,26-42]$.

A review study of Scherrer et al. in 2010 revised studies looking at dentin bond strength and not enamel. The results of this study, indicated that microtensile test results in less mean values on enamel than on dentin due to microfractures that occured during stick cutting procedures in the former [43]. In this study, all pre-test failures were considered as $0 \mathrm{MPa}$. Conversely, since the bonded area is larger in macrotensile tests, lower values could have been expected. Yet, the lack of pretest failures due to the nature of the macrotensile test, namely bonded specimens are only subjected to tensile forces without any cutting procedures, macrotensile test delivered higher results. However, in the review of Scherrer et al, the reviewed material did not include the pretest failures as zero value but excluded them from statistical analysis [43]. This might have caused the discrepancy in the mean values between the reported values and those of ours. It has to be noted however that in the review of Scherrer big variation was noted between the results of the reviewed papers [43]. On the contrary, our results, even though pretest failures were recorded as zero values, presented lower standard deviation that could be also traced in the Weilbull statistics.

Bond strength results in adhesion studies should be also interpreted with failure types. Cohesive failures in the substrate (Score 1) and combination of adhesive and cohesive failure types in the substrate and bonding agent (Score 2) indicate that bond strength of the adhesive system and the resin composite exceeds that of the cohesive strength of the substrate. Regardless of the test method, the incidence of Score 1 and Score 2 were more frequent in enamel than in dentin. Thus, when these two failure types are considered, adhesion to enamel could be considered more reliable than to dentin. Although the focus was on the adhesion of the resin based materials to enamel and dentin, it has to be noted that bond strength of the adhesive resin to the resin composite also plays a significant role in interpreting failure types. Score 3,4 and 5 are also influenced by the adhesive-composite adhesion. The incidence of Score 5 that is the cohesive failure in the resin composite was almost only experienced with $\mu$ TBT method for both enamel and dentin. Thus, this type of score reveals that adhesion to both enamel and dentin exceeded that to the resin composite. In that respect, $\mu \mathrm{TBT}$ indicates that adhesion is reliable to the both substrates at least with the tested specimens left after pre-test failures.

Clinical conditions during chewing functions expose restorative materials to multiple strains in different directions that could be a combination of both shear and tensile. Fracture toughness test and interpretation of fracture mechanics was recently considered as an alternative to other bond measurement methods as it considers the visco-elastic nature of the tested materials better than the commonly used bond strength methods. Unfortunately, the preparation technique is usually more complex than most bond tests and also the stresses presented within the adhesive resin are quite complex [44]. The overabundant number of adhesive resin and resin-based composites in restorative dentistry would possibly continue to be tested and ranked prior to clinical trials. Due to technique sensitivity in specimen preparation, only one test method could not be advised for adhesion studies in dentistry. Hence, ranking of materials could be made based on the research question where $\mu \mathrm{SBT}$ could be considered less technique sensitive and $\mu$ TBT could be used for testing worse case scenarios. Future studies should also involve pulp pressure, the use of disinfectants and the effects of possible contaminants such as provisional cements especially on dentin $[45,46]$. 


\section{Conclusions}

From this study, the following could be concluded:

(1) Adhesion of resin composite to enamel was significantly higher with SBT, TBT and $\mu$ SBT methods than with $\mu$ TBT but adhesion to dentin did not show significant difference depending on the test method.

(2) Only with SBT, significant difference was observed for bond values between enamel and dentin.

(3) Weibull distribution showed more reliable adhesion of the resin composite to enamel-SBT/ $\mu$ SBT and dentin- $\mu$ SBT compared to substrate-test combinations.

(4) $\mu$ TBT resulted in frequent pre-test failures more commonly with enamel than with dentin. Regardless of the test method, cohesive substrates in substrate were more frequent in enamel than in dentin, indicating more reliable adhesion to enamel.

\section{Clinical relevance}

Based on the bond strength values, Weibull modulus and the failure types, adhesion to enamel is more reliable than to dentin. $\mu$ SBT test could be considered more suitable for testing adhesion of resin-based materials to enamel or dentin.

\section{Acknowledgements}

The authors acknowledge Mr A. Trottmann, University of Zürich, Center for Dental and Oral Medicine, Zürich, Switzerland, for his assistance with the specimen preparation, Mrs M. Roos, Division of Biostatistics, Institute of Social and Preventive Medicine, University of Zurich, Switzerland for her support with the statistical analysis and Cavex, Haarlem, The Netherlands for generous provision of the composite materials.

\section{Disclosure statement}

No potential conflict of interest was reported by the authors.

\section{References}

[1] Schwartz RS. Fundamentals of operative dentistry: a contemporary approach. Chicago: Quintessence books; 1996. p. 209.

[2] Kugel G, Ferrari M. The science of bonding: from first to sixth generation. J Am Dent Assoc. 2000;131:20S-25S.

[3] Joniot SB, Grégoire GL, Auther AM, et al. Three-dimensional optical profilometry analysis of surface states obtained after finishing sequences for three composite resins. Oper Dent. 2000;25:311-315.

[4] Yoshiyama M, Matsuo T, Ebisu S, et al. Regional bond strengths of self-etching/self-priming adhesive systems. J Dent. 1998;26:609-616.

[5] Carvalho RM, Ciuchi B, Sano H, et al. Resin diffusion through demineralized dentin matrix. J Appl Oral Sci. 1999;13:417-424.

[6] Van Meerbeek B, De Munck J, Yoshida Y, et al. Buonocore memorial lecture. Adhesion to enamel and dentin: current status and future challenges. Oper Dent. 2003;28:215-235. 
[7] Spencer P, Wang Y, Walker MP, et al. Molecular structure of acid-etched dentin smear layers - in situ study. J Dent Res. 2007;80:1802-1807.

[8] De Munck J, Mine A, Poitevin A, et al. Meta-analytical review of parameters involved in dentin bonding. J Dent Res. 2012;91:351-357.

[9] Van Meerbeek B, Peumans M, Poitevin A, et al. Relationship between bond strength tests and clinical outcomes. Dent Mater. 2010;26:e100-e121.

[10] Griffith AA. The phenomena of rupture and flow in solids. Philos Trans R Soc London, Ser A. 1920;221:168-198.

[11] Valandro LF, Özcan M, Amaral R, et al. Effect of testing methods on the bond strength of resin to zirconia-alumina ceramic: microtensile versus shear test. Dent Mater J. 2008;27:849-855.

[12] Human Research Ordinance (810.301), Art. 30.

[13] World Medical Association (WMA). Declaration of Helsinki - ethical principles for medical research involving human subjects. 64th WMA General Assembly; 2013 Oct; Fortaleza, Brazil.

[14] Human Research Act (810.30), Art. 2 and 32, Human Research Ordinance (810.301), Art. 25.

[15] ISO/TS 11405. Dental materials - testing of adhesion to tooth structure; 2003.

[16] Yang B, Ludwig K, Adelung R, et al. Micro-tensile bond strength of three luting resins to human regional dentin. Dent Mater. 2006;22:45-56.

[17] Koibuchi H, Yasuda N, Nakabayashi N. Bonding to dentin with a self-etching primer: the effect of smear layers. Dent Mater. 2001;17:122-126.

[18] Della Bona A, Van Noort R. Shear vs. tensile bond strength of resin composite bonded to ceramic. J Dent Res. 1995;74:1591-1596.

[19] Versluis A, Tantbirojn D, Douglas WH. Why do shear bond tests pull out dentin? J Dent Res. 1997;76:1298-1307.

[20] Betamar N, Cardew G, van Noort R. Influence of specimen designs on the microtensile bond strength to dentin. J Adhes Dent. 2007;9:159-168.

[21] Armstrong S, Geraldeli S, Maia R, et al. Adhesion to tooth structure: a critical review of 'micro' bond strength test methods. Dent Mater. 2010;26:e50-e62.

[22] Meredith N, Sherriff M, Setchell DJ, et al. Arch Oral Biol. 1996;41:539-545.

[23] Van Meerbeek B, De Munck J, Yoshida Y, et al. Buonocore memorial lecture. Adhesion to enamel and dentin: current status and future challenges. Oper Dent. 2003;3:215-235.

[24] Woronko GAJ, St Germain HAJ, Meiers JC. Effect of dentin primer on the shear bond strength between composite resin and enamel. Oper Dent. 1996;21:116-121.

[25] Lattaa MA. Shear bond strength and physicochemical interactions of XP bond. J Adhes Dent. 2007;9:245-248.

[26] Lührs AK, Guhr S, Schilke R, et al. Shear bond strenght of self-etch adhesives to enamel with additional phosphoric acid etching. Oper Dent. 2008;33:155-162.

[27] Mahmoud SH, Abdel Kader Sobh M, Zaher AR, et al. Bonding of resin composite to tooth structure of uremic patients receiving hemodialysis: shear bond strength and acid-etch patterns. . Adhes Dent. 2008;10:335-338.

[28] Krifka S, Börzsönyi A, Koch A, et al. Bond strength of adhesive systems to dentin and enamel - human vs. bovine primary teeth in vitro. Dent Mater. 2008;24:888-894.

[29] Frankenberger R, Lopes M, Perdigão J, et al. The use of flowable composites as filled adhesives. Dent Mater. 2002;18:227-238.

[30] Ferrari M, Goracci C, Sadek F, et al. Microtensile bond strength tests: scanning electron microscopy evaluation of sample integrity before testing. Eur J Oral Sci. 2002;110:385-391.

[31] Lührs AK, Guhr S, Günay H, et al. Shear bond strength of self-adhesive resins compared to resin cements with etch and rinse adhesives to enamel and dentin in vitro. Clin Oral Invest. 2010;14:193-199.

[32] McCabe JF, Rusby S. Dentine bonding - the effect of pre-curingthe bonding resin. Br Dent J. 1994;176:333-336.

[33] Leirskar J, Oilo G, Nordbø H. In vitro shear bond strength of two resin composites to dentin with five different dentin adhesives. Quintessence Int. 1998;29:787-792.

[34] Pioch T, Kobaslija S, Schagen B, et al. Interfacial micromorphology and tensile bond strength of dentin bonding systems after $\mathrm{NaOCl}$ treatment. J Adhes Dent. 1999;1:135-142. 
[35] McCabe JF, Rusby S. Dentine bonding - the effect of pre-curingthe bonding resin. Br Dent J. 1994;176:333-336.

[36] Belli R, Baratieri LN, Braem M, et al. Tensile and bending fatigue of adhesive interface to dentin. Dent Mater. 2010;26:1157-1165.

[37] Frankenberger R, Lohbauer U, Tay FR, et al. The effect of different air-polishing powders on dentin bonding. J Adhes Dent. 2007;9:381-389.

[38] Frankenberger R, Lohbauer U, Taschner M, et al. Adhesive luting revisited: influence of adhesive, temporary cement, cavity cleaning, and curing mode on internal dentin bond strength. J Adhes Dent. 2007;9:269-273.

[39] Gernhardt CR, Bekes K, Hahn P, et al. Influence of pressure application before light-curing on the bond strength of adhesive systems to dentin. Braz Dent J. 2008;19:62-67.

[40] Gernhardt CR, Kielbassa AM, Hahn P, et al. Tensile bond strengths of four different dentin adhesives on irradiated and non-irradiated human dentin in vitro. J Oral Rehabil. 2001;28:814820.

[41] Frankenberger R, Pashley DH, Reich SM, et al. Charcterisation of resin-dentine interfaces by compressive cyclic loading. Biomaterials. 2005;26:2043-2052.

[42] Ding PG, Wolff D, Pioch T, et al. Relationship between microtensile bond strength and nanoleakage at the composite-dentin interface. Dent Mater. 2009;25:135-141.

[43] Scherrer SS, Cesar PF, Swain MV. Direct comparison of the bond strength results of the different test methods: a critical literature review. Dent Mater. 2010;26:e78-e93.

[44] Soderholm kJ. Review of the fracture toughness approach. Dent Mater. 2010;26:e63-e77.

[45] Frankenberger R, Lohbauer U, Taschner M, et al. Adhesive luting revisited: influence of adhesive, temporary cement, cavity cleaning, and curing mode on internal dentin bond strength. J Adhes Dent. 2007;9:269-273.

[46] Özcan M, Lamperti S. Effect of mechanical and air-particle cleansing protocols of provisional cement on immediate dentin sealing layer and subsequent adhesion of resin composite cement. J Adhes Sci Technol. 2015;29:2731-2743. 